University of Nebraska - Lincoln

DigitalCommons@University of Nebraska - Lincoln

Pathogenicity and Molecular Characterization of Emerging Porcine Reproductive and Respiratory Syndrome Virus in Vietnam in 2007

\author{
S. Metwally \\ USDA, Samia.A.Metwally@aphis.usda.gov \\ F. Mohamed \\ USDA \\ K. Faaberg \\ USDA \\ T. Burrage \\ PIADC \\ M. Prarat \\ USDA \\ See next page for additional authors \\ Follow this and additional works at: https://digitalcommons.unl.edu/usdaarsfacpub \\ Part of the Agricultural Science Commons
}

Metwally, S.; Mohamed, F.; Faaberg, K.; Burrage, T.; Prarat, M.; Moran, K.; Bracht, A.; Mayr, G.; Berninger, M.; Koster, L.; To, T. L.; Nguyen, V. L.; Reising, M.; Landgraf, J.; Cox, L.; Lubroth, J.; and Carrillo, C., "Pathogenicity and Molecular Characterization of Emerging Porcine Reproductive and Respiratory Syndrome Virus in Vietnam in 2007" (2011). Publications from USDA-ARS / UNL Faculty. 571. https://digitalcommons.unl.edu/usdaarsfacpub/571

This Article is brought to you for free and open access by the U.S. Department of Agriculture: Agricultural Research Service, Lincoln, Nebraska at DigitalCommons@University of Nebraska - Lincoln. It has been accepted for inclusion in Publications from USDA-ARS / UNL Faculty by an authorized administrator of DigitalCommons@University of Nebraska - Lincoln. 


\section{Authors}

S. Metwally, F. Mohamed, K. Faaberg, T. Burrage, M. Prarat, K. Moran, A. Bracht, G. Mayr, M. Berninger, L. Koster, T. L. To, V. L. Nguyen, M. Reising, J. Landgraf, L. Cox, J. Lubroth, and C. Carrillo 
ORIGINAL ARTICLE

\title{
Pathogenicity and Molecular Characterization of Emerging Porcine Reproductive and Respiratory Syndrome Virus in Vietnam in 2007
}

\author{
S. Metwally ${ }^{1}$, F. Mohamed ${ }^{1}$, K. Faaberg ${ }^{2}$, T. Burrage ${ }^{3}$, M. Prarat ${ }^{1}$, K. Moran ${ }^{1}$, A. Bracht ${ }^{1}$, G. Mayr ${ }^{1}$,
} M. Berninger ${ }^{1}$, L. Koster ${ }^{4}$, T. L. To ${ }^{5}$, V. L. Nguyen ${ }^{5}$, M. Reising ${ }^{6}$, J. Landgraf ${ }^{4}$, L. Cox ${ }^{4}$, J. Lubroth ${ }^{7}$ and C. Carrillo ${ }^{1}$

${ }^{1}$ FAO Reference Center for Vesicular Diseases, USDA, APHIS, Foreign Animal Disease Diagnostic Laboratory, National Veterinary Service Laboratories (NVSL), Plum Island Animal Disease Center (PIADC), Greenport, NY, USA

${ }^{2}$ National Animal Disease Center, USDA, ARS, Ames, IA, USA

${ }^{3}$ Department of Homeland Security, PIADC, Greenport, NY, USA

${ }^{4}$ USDA, APHIS, NVSL, Ames, IA, USA

${ }^{5}$ National Center for Veterinary Diagnosis, Dong-da, Hanoi, Vietnam

${ }^{6}$ USDA, APHIS, Center for Veterinary Biologics, Ames, IA, USA

${ }^{7}$ Food and Agriculture Organization (FAO), Rome, Italy

Keywords:

PRRS; pathogenicity; emerging; Vietnam outbreak

\section{Correspondence:}

S. Metwally. Foreign Animal Disease Diagnostic Laboratory, National Veterinary Service Laboratories (NVSL), Plum Island Animal Disease Center (PIADC), Greenport, NY, USA. Tel.: +1 631323 3322;

Fax: +1 631323 3366;

E-mail: Samia.A.Metwally@aphis.usda.gov

Received for publication February 10, 2010

doi:10.1111/j.1865-1682.2010.01152.x

\section{Summary}

In 2007, Vietnam experienced swine disease outbreaks causing clinical signs similar to the 'porcine high fever disease' that occurred in China during 2006. Analysis of diagnostic samples from the disease outbreaks in Vietnam identified porcine reproductive and respiratory syndrome virus (PRRSV) and porcine circovirus type 2 (PCV-2). Additionally, Escherichia coli and Streptococcus equi subspecies zooepidemicus were cultured from lung and spleen, and Streptococcus suis from one spleen sample. Genetic characterization of the Vietnamese PRRSV isolates revealed that this virus belongs to the North American genotype (type 2) with a high nucleotide identity to the recently reported Chinese strains. Amino acid sequence in the nsp2 region revealed $95.7-99.4 \%$ identity to Chinese strain HUN4, 68-69\% identity to strain VR-2332 and $58-59 \%$ identity to strain MN184. A partial deletion in the nsp2 gene was detected; however, this deletion did not appear to enhance the virus pathogenicity in the inoculated pigs. Animal inoculation studies were conducted to determine the pathogenicity of PRRSV and to identify other possible agents present in the original specimens. Pigs inoculated with PRRSV alone and their contacts showed persistent fever, and two of five pigs developed cough, neurological signs and swollen joints. Necropsy examination showed mild to moderate bronchopneumonia, enlarged lymph nodes, fibrinous pericarditis and polyarthritis. PRRSV was re-isolated from blood and tissues of the inoculated and contact pigs. Pigs inoculated with lung and spleen tissue homogenates from sick pigs from Vietnam developed high fever, septicaemia, and died acutely within $72 \mathrm{~h}$, while their contact pigs showed no clinical signs throughout the experiment. Streptococcus equi subspecies zooepidemicus was cultured, and PRRSV was re-isolated only from the inoculated pigs. Results suggest that the cause of the swine deaths in Vietnam is a multifactorial syndrome with PRRSV as a major factor. 


\section{Introduction}

Porcine reproductive and respiratory syndrome virus (PRRSV) causes reproductive failure of sows and respiratory disease of piglets and growing pigs. The disease occurs in most pig-producing countries worldwide and has a high economic impact on the global swine industry. The aetiological agent is a positive, single-stranded RNA virus of approximately $15.5 \mathrm{~kb}$ in length and is a member of the Arteriviridae family in the order Nidovirales (Cavanagh, 1997). Based on the genetic differences seen in the prototype strains Lelystad (Meulenberg et al., 1993) and VR2332 (Nelsen et al., 1999), PRRSV has been historically classified in two major genotypes: the European-like strains (type 1; prototype Lelystad) and the North American-like strains (type 2; prototype VR-2332). The two major genotypes share about $60 \%$ identity on the nucleotide level, while individual PRRSV isolates within genotypes can vary up to approximately $20 \%$ in nucleotide sequence. PRRSV undergoes remarkable genetic alteration, perhaps related to its ability to undergo high frequency viral recombination (Yuan et al., 1999, 2000, 2001, 2004; van Vugt et al., 2001). The high degree of genetic and antigenic diversity adds to the complexity of control and eradication of the disease.

Porcine reproductive and respiratory syndrome virus is present in nature and causes a variety of clinical signs including reproductive problems (abortions, pre-mature birth and infertility), loss of appetite, coughing, high fever, respiratory distress and death in severe cases. Unlike typical cases of PRRSV infection that may cause high mortality rates in young pigs (Collins et al., 1992; Wensvoort et al., 1992, Meredith, 1993; Murtaugh et al., 1993, Wensvoort, 1993; Batista et al., 2002), the highly pathogenic PRRSV causes outbreaks leading to high mortality in adult animals (Feng et al., 2008; An et al., 2010). In 2006, an atypical, highly pathogenic form of PRRSV affected more than 2 million pigs causing deaths of at least 400000 pigs from June to September 2006 in at least 10 Chinese provinces (Tian et al., 2007a). Despite efforts to control the outbreaks in China in 2006 through containment, slaughter and vaccination, the disease continued to spread throughout the country and across international borders.

Here, we describe a complete diagnostic investigation of samples from the 2007 outbreaks in Vietnam, the isolation and genetic characterization of the PRRSV isolates, and the disease pathogenicity in naïve pigs under experimental conditions.

\section{Materials and Methods}

\section{Outbreak and sample collection}

In March 2007, swine disease outbreaks causing respiratory distress, high fever, constipation and diarrhoea first occurred in Hai Duong (HD) province in northern Vietnam. Disease rapidly spread to six other provinces of the Red River Delta, namely Hung Yen (HY), Quang Ninh (QNi), Thai Binh (TB), Bac Ninh (BN), Bac Giang (BG) and Hai Phong (HP) with thousands of pigs affected (Fig. 1). In spite of placing strict control measures to prevent disease spread, several cases were reported in Quang Nam (QN) province in central Vietnam by June, and in surrounding provinces of Thua Thien Hue (TTH), Da Nang (DN) and Quang Ngai (QNg) with more than 32000 pigs affected and 23\% mortality. By July, the disease outbreaks spread to Long An (LA) and Ba Ria Vung Tau (BR-VT) provinces in the South. Lungs and spleens collected from three affected pigs from Thang Binh $(\mathrm{TgB})$ district in the central province of $\mathrm{QN}$, and lung and lymph node homogenates collected from four pigs from TB, BG, HY and Ha Noi $(\mathrm{HN})$ were submitted for analysis to the National Veterinary Service Laboratories, (NVSL); Foreign Animal Disease Diagnostic Laboratory (FADDL), Greenport, NY USA; the Diagnostic Virology Laboratory and Diagnostic Bacteriology Laboratory in Ames, IA USA. This submission was organized and facilitated by the Food and Agriculture Organization (FAO) of the United Nations, Rome, Italy. Field clinical observations indicated an outbreak characterized by high fever, respiratory distress, blue ears, skin haemorrhages, stillbirths, abortions, high morbidity and increased mortality.

\section{Diagnostic approach}

Virus isolation (VI) in cell culture, polymerase chain reaction (PCR) tests, nucleic acid sequence analysis, electron microscopy (EM), standard bacteriological culture methods and serological assays were performed to rule out African swine fever (ASF), classical swine fever (CSF), foot-and-mouth disease (FMD), swine vesicular disease (SVD), porcine circovirus type 2 (PCV2), porcine teschovirus (PTV) and PRRSV. Tissue specimens were also inoculated in a number of cell lines to look for any other potential viral agents. Animal inoculation studies were conducted using original specimens and cell culture positive extracts to determine the PRRSV virulence and to identify other possible pathogenic agents present in the original tissues not readily cultured by standard methods.

\section{Virus isolation}

Several Tissues were prepared as $10 \% \mathrm{w} / \mathrm{v}$ homogenates in Hank's minimal essential media with antibiotics. Confluent $25 \mathrm{~cm}^{2}$ cell culture flasks were inoculated with $500 \mathrm{ul}$ of the sample. Alternatively, $50 \mathrm{ul} /$ well was used to inoculate 96-well plates. The following tissue culture cells were used: secondary lamb kidney (LK), Instituto Biologico Rim 


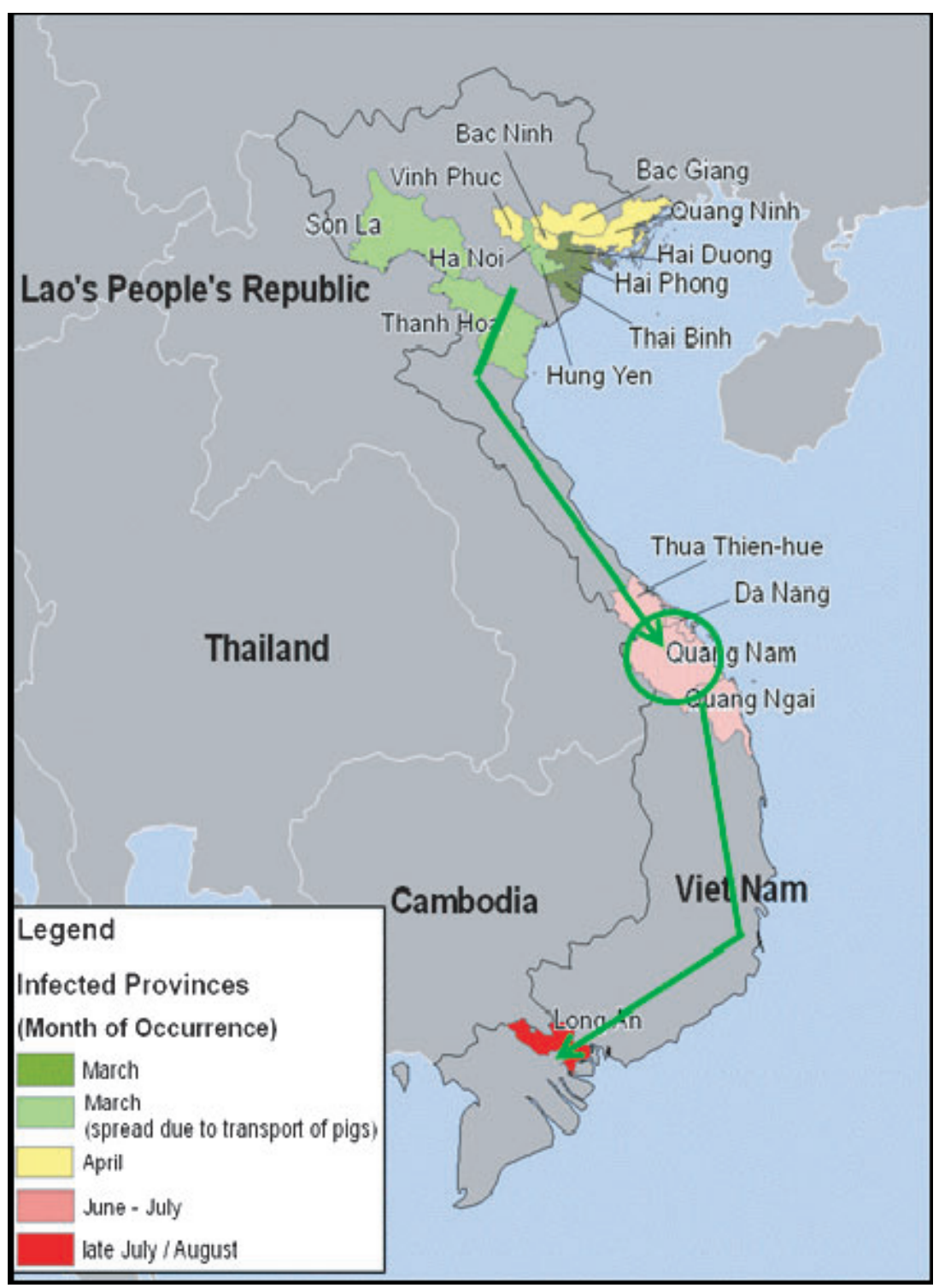

Fig. 1. Vietnam map. Outbreaks spreading from north to south (arrow) in 2007. Disease outbreaks first reported in the northern province of Vietnam and spread to central and southern provinces (arrows). Specimens submitted for testing were collected from Hai Duong district in April and from Qaung Nam district in June 2007.

Suino-2 swine kidney (IBRS-2), Vero, swine kidney-6 (SK-6), primary swine peripheral blood mononuclear (PBMC) and MARC-145. Monolayers were monitored for cytopathic effect (CPE) for two consecutive blind passages; LK and IBRS-2 3 days per passage, and Vero, SK-6, MARC-145 and PBMC 7 days per passage. For CSF virus detection, SK-6 cells were inoculated and stained $72 \mathrm{~h}$ post-inoculation for the presence of CSF antigen using an immunohistochemistry assay (ABC- avidin biotin complex assay) utilizing V3 monoclonal antibody. An additional set of PBMC were inoculated and monitored for CPE and rosette formation (hemagglutination) as evidence of ASF virus (ASFV) infection. MARC-145 cells were inoculated and monitored for CPE in attempt to isolate PRRSV.

\section{Serology and bacteriology}

The presence of PRRSV antibodies was tested using the PRRS HerdChek 2XR ELISA kit from IDEXX Laboratories (Westbrook, ME, USA). The test was performed on samples collected from the animal inoculation study as explained later. The sample to positive $(\mathrm{S} / \mathrm{P})$ ratio was calculated according to manufacturer's specifications. Standard methods of bacteriology were used for analysis of the spleen, lung and lymph nodes. 

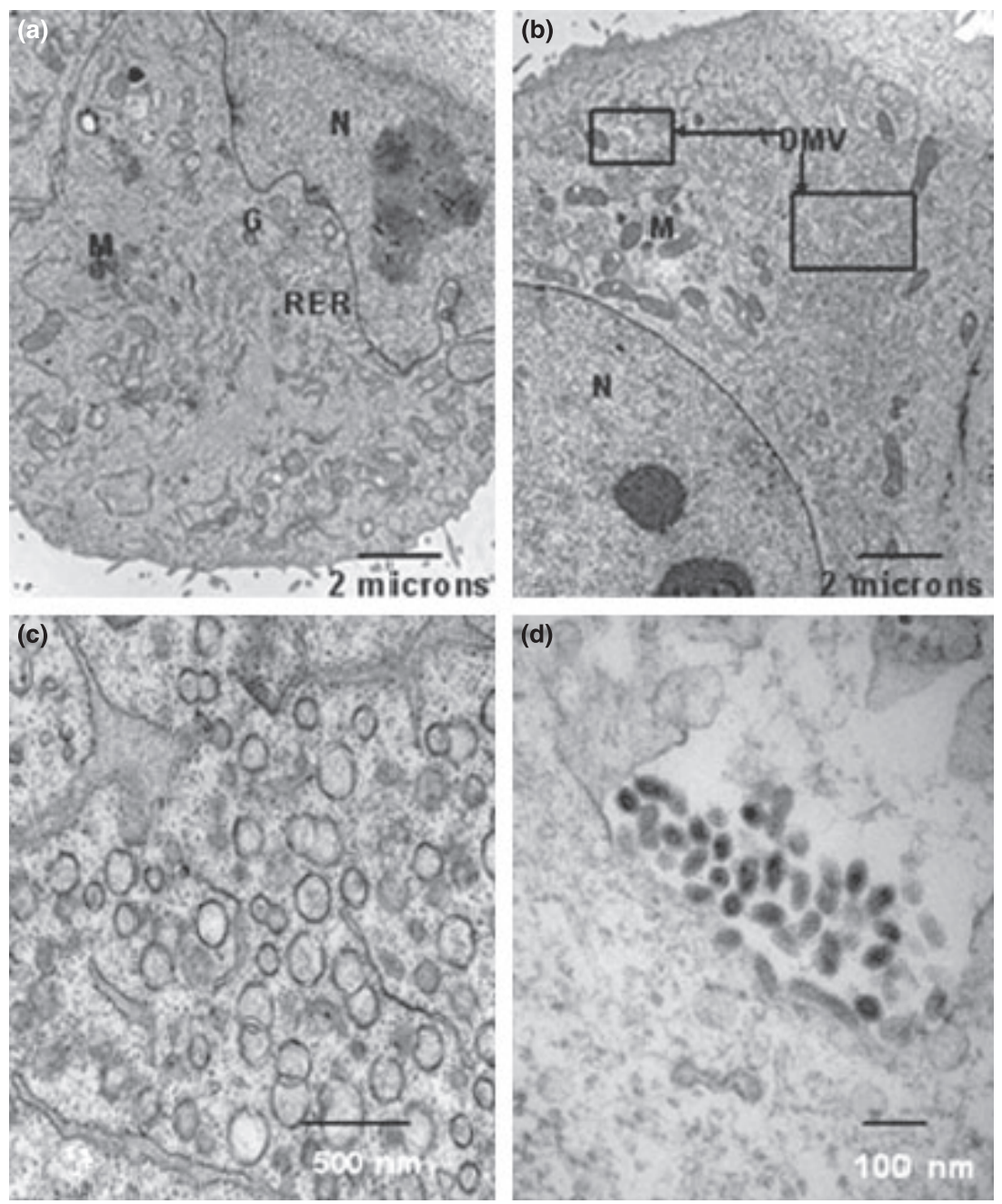

Fig. 2. Electron micrographs of mock and Vietnam isolate infected-MARC-145 cells. (a) Mock infected MARC-145, mitochondria (M), rough endoplasmic reticulum (RER) nucleus (N). (b) Vietnam-isolate infected cells showing changes in mitochondria (M) and nucleus (N). Cytoplasm filled with double membrane vesicles (DMV), a high power view is shown in plates C and D. (c) Clusters of cytoplasmic double-membrane vesicles. (d) Extracellular clumps of mature 40-50 nm electron-dense particles.

Immunofluorescence and Electron Microscopy

MARC-145 cell cultures infected with Vietnam isolates showing $>50 \%$ CPE were prepared for immunofluorescence assay (IFA) and transmission EM. For IFA, the cells were fixed with $100 \%$ acetone at $-20^{\circ} \mathrm{C}$ for $10 \mathrm{~min}$, rinsed in phosphate-buffered saline (PBS), blocked with $10 \%$ foetal calf serum in PBS (FCS-PBS), incubated with a $1: 100$ dilution of anti-PRRSV Mab, SDOW17 (Nelson et al., 1993), in FCS-PBS for $1 \mathrm{~h}$, washed and incubated with anti-mouse antibody conjugated to Alexa Fluor ${ }^{\circledR} 488$ Dye (Molecular probes, Eugene, OR, USA).

For EM examination, the cells were fixed with a solution containing $2 \%$ glutaraldehyde, $2 \mathrm{~mm}$ calcium carbonate and 0.1 M HEPES buffer ( $\mathrm{pH}$ 7.4). The cells were then osmicated, stained en bloc with uranyl acetate and embedded in Spurr's Resin via acetone dehydration. Tonsil, lymph node, liver, spleen and lung from experimental pigs inoculated with tissue homogenate or PRRSV were harvested at necropsy and processed for EM as noted earlier. For tissue orientation, $1-\mu \mathrm{m}$-thick resin tissue sections were stained with $1 \%$ Toluidine Blue and examined with a Zeiss microscope. Ultrathin sections of cells and tissues were picked up on Formvar and carbon-coated slot grids, stained with uranyl acetate and lead citrate and examined using a Hitachi $\mathrm{T}-7600$ electron microscope operating at $80 \mathrm{kV}$. Electron microscope images were captured with an advanced microscopy techniques (AMT) digital camera and contrast adjusted using Adobe Photoshop software (Adobe Systems Inc., San Jose, CA, USA). 


\section{Polymerase chain reaction}

For reverse transcriptase PCR tests (RT-PCR), RNA was extracted from $140 \mu \mathrm{l}$ of tissue homogenate or cell culture supernatant using RNeasy extraction kit (Qiagen, Stanford, CA, USA), following the manufacturer specifications. RNA was eluted in $40 \mu \mathrm{l}$ of RNase-free water and stored at $-70^{\circ} \mathrm{C}$. Similarly, for PCR tests, DNA was extracted from $200 \mu \mathrm{l}$ of tissue homogenate or cell culture supernatant using DNeasy extraction kit (Qiagen), following the manufacturer specifications. DNA was eluted in $100 \mu \mathrm{l}$ of RNase-free water and stored at $-70^{\circ} \mathrm{C}$. Original specimens and virus culture passages with $\mathrm{CPE}$ were tested for the presence of nucleic acid of PCV-2, porcine enterovirus (Zell et al., 2000, Krumbholz et al., 2003), CSF virus (CSFV) (Risatti et al., 2003), ASFV (Zsak et al., 2005), FMD virus (FMDV) (Callahan et al., 2002) SVD (Callens and De Clercq, 1999) and PRRSV (G.R. Risatti, personal communication) as described in their respective published references.

\section{Sequence analysis}

Nucleic acid sequences for non-structural protein 2 (nsp2), open reading frame 5 (ORF5) and ORF6 of the original and cultured PRRSV from Vietnam were obtained. The original homogenate (lymph node and lung) of pig 07-HN and a pool of macrophage virus culture/passage 1 of the following pigs: 07-TB, 07-BG, 07HY, 07-HN, 07-QN-1, 07-QN-2 and 07-QN-3 were used. Sequences were obtained using the following primers: 14682-F: 5'-CTTGCTAGGCCGCAAGTACAT and 15396R: 5'-TAATTTCGGCCGCATGGTT, which amplified a 714-bp product containing ORF-6; primers in positions 13562-F: 5'-TGCTTCYGAGATGAGTGAAA and 14525-R: 5'-CAAAAGGTGCAGAAGCCCTA, resulted in an amplification product of $964 \mathrm{bp}$ from ORF5, and 2492-F: 5'GRACTTCCTCARCTTCTTGC and 3160-R: 5'TCGACGAGCTTAAAGACCAGA yielded an amplification product of 669 bp from the nsp 2 genomic region. Amplified products were column purified (Qiagen) and cloned in TOPO-TA cloning system (Invitrogen, Carlsbad, CA, USA). After transforming into bacteria, at least three colonies of each construct were selected and grown in $3 \mathrm{ml}$ of Carbenicillin-LB media $(20 \mathrm{mg} / \mathrm{l})$. Plasmid DNA was purified using S.N.A.P. ${ }^{\mathrm{TM}}$ MiniPrep Kit (Invitrogen) and sequenced in ABI 3900 automated sequencer (Applied Biosystems, Foster City, CA, USA).

Sequences were assembled using the Sequencher ${ }^{\circledR}$ program (Gene Codes Corporation, Ann Arbor, MI, USA) and submitted to GenBank ${ }^{\circledR}$ database Basic Local Alignment Search Tool (BLASTn) for analysis (Benson et al., 2008).

For phylogenetic studies, sequences were aligned to public (GenBank) and an internal PRRSV database con- taining over 8600 viruses detected in North America, using the Megaline ${ }^{\circledR}$ software package (DNASTAR, Inc, Madison, WI, USA).

\section{Animal inoculation study}

Twelve 4- to 6-week-old Yorkshire pigs were purchased from a PRRS-free herd and were pre-tested negative for antibodies to PRRSV, PCV-2, pseudorabies virus, transmissible gastroenteritis virus and swine influenza virus (H1N1 and H3N2). Pigs were acclimated at Plum Island Animal Disease Center (PIADC) biocontainment Biosafety Level 3 Agriculture facility for 10 days before the start of the experiment, observed daily for clinical signs, and body temperature was recorded throughout the experiment starting 3 days prior to inoculation.

Animals were divided into three groups. Group one consisted of three pigs that received intranasal (IN), intramuscular (IM) and intraperitoneal (IP) inoculation of $10 \%$ unfiltered, original tissue homogenate obtained from sick pigs from Vietnam (spleen and lung), $1 \mathrm{ml}$ per route. Two days post-inoculation (dpi), two naïve pigs were introduced and comingled with the inoculated pigs. Group two consisted of three pigs that received one $\mathrm{ml}$ per route IN, IM and IP of pooled PRRSV/ PBMC passage one composite of individually inoculated lymph nodes, lung and spleen. Inoculum contained $10^{4.5}$ $\mathrm{TCID}_{50} / \mathrm{ml}$ of PRRSV titrated on PBMC, corresponding to $10^{3.7} \mathrm{TCID}_{50} / \mathrm{ml}$ when titrated on MARC- 145 cells. At 2 dpi, two naïve pigs were introduced and comingled with the inoculated pigs. Group three consisted of two sham-inoculated control pigs; one pig was inoculated with EMEM media used for making the tissue homogenate, and the other pig was inoculated with the negative control PBMC culture supernatant with the same lot used for virus propagation. Pigs were monitored daily for fever and clinical signs. Serum and heparinized blood were collected at $0,2,5,7,9,12,15,22$, and $28 \mathrm{dpi}$ or day post-contact $(\mathrm{dpc})$, with day 0 representing the day of inoculation or first day of contact. White blood cell (WBC) counts were performed on heparinized blood using a Beckman Coulter Counter (Beckman Coulter, Inc., Miami, FL 33196, USA), and sera were used for PRRSV isolation and detection by reverse transcriptase PCR (RT-PCR). Animals were necropsied at the end of the experiment or when died or euthanized because of severe illness. At the time of necropsy, a complete set of fresh tissues was collected for bacteriology, virology and PCR analysis, and a set of tissues was fixed in $10 \%$ neutral-buffered formalin for histopathology. The animal experiment was performed in compliance with an Animal Use Protocol and all the regulations of the Institutional Animal Care and Use Committee (IACUC). 


\section{Results}

\section{Diagnostic submission}

Tissue homogenates of lung and lymph nodes, and tissue samples of spleen, lung and lymph node from seven affected pigs from five districts in the northern and central provinces of Vietnam tested negative for CSFV, FMDV and SVD virus by both virus isolation and RTPCR, negative for ASFV by both virus isolation and PCR, and negative for PTV (formerly porcine enterovirus serotype 1) by RT-PCR. PBMC cell cultures inoculated with spleen and/or lung samples from the seven pigs showed CPE with no rosette formation. RT-PCR confirmed the presence of PRRSV nucleic acid and the absence of CSFV, and PCR the absence of ASFV on CPE-positive PBMC; however, MARC-145 did not support the growth of PRRSV from samples collected from QN province. Samples from the three pigs from the QN province were positive for PCV-2 by PCR, while samples from the provinces of TB, BG, HY and HN were negative (Table 1).

Escherichia coli and Streptococcus equi subsp. zooepidemicus were cultured from lungs and spleens, and Streptococcus suis from one spleen sample from the QN province (Table 1).

PBMC-inoculated cells revealed intense cytoplasmic staining by IFA with the anti-PRRS MAb SDOW17, which reacts to an epitope on the $15 \mathrm{kDA}$ nucleocapsid protein of the PRRSV but not with the p54 anti-ASFV MAb (data not shown). Electron microscopy of ultrathin sections of infected swine PBMC revealed cytoplasmic proliferations of single $(35-40 \mathrm{~nm})$ and double $(70-85 \mathrm{~nm})$ membrane structures. Extracellular clumps of $50 \mathrm{~nm}$ particles were seen in cells infected with the Vietnamese isolates as well as with PRRSV reference strain (Fig. 2).

All samples except for the lung of pig 07QN-2 were positive for PRRSV nucleic acid by RT-PCR (Table 1 ).
Results of PRRS RT-PCR were confirmed through sequencing of the ORF6 amplification product. The four samples from the QN province were PCR positive for PCV-2. The PCV-2 PCR results were confirmed by restriction enzymatic digestion of the PCR product with NcoI that digests the PCV PCR product in two easily distinguishable fragments of 168 and $75 \mathrm{bp}$ each (Fenaux et al., 2000).

\section{Sequences and phylogenetic analysis}

Sequence analysis of targeted genomic regions amplified from the original $10 \%$ lung and lymph node homogenate of pig 07HN, swine PBMC infected with 07HN homogenate, and a pool PBMC culture/passage of pigs, 07TB, 07BG, 07HY, 07HN, 07QN-1, 07QN-2 and 07QN-3 (Table 1), confirmed that the Vietnam 2007 PRRSV isolates belong to the North American PRRSV genotype (Type 2) and have a close identity with the recently reported Chinese strains with the identical deletions in the nsp2 region. The BLAST search of the Vietnamese ORF6 sequence against the whole nucleotide GenBank database confirmed 99\% homology with the following Chinese PRRSV strains: HUN4, JX0612, JXA1, HUB2, HUB1, HuN and HEB 1. All these strains had been identified during the recent high virulent PRRSV epidemic in China (Tian et al., 2007a; Tong et al., 2007; An et al., 2010).

Sequence alignments of the 2006 Chinese strain HUN4 and the 2007 Vietnamese sequences generated from the highly variable genomic region ORF4-6 showed 99.499.7\% nucleotide identity, whereas identity of the Vietnam isolates to the North American prototype strain VR-2332 (Type 2) and to the highly virulent North American strain MN184 was approximately $90 \%$ and 86-88\%, respectively. Similarly, nsp2 region nucleotide comparison showed that the Vietnamese isolates have

Table 1. Diagnostic results on samples from a swine disease outbreak in Vietnam. Samples analysed using PRRSV conventional polymerase chain reaction (PCR), virus isolation (VI) on swine peripheral blood macrophage cell (PBMC) and MARC-145 cells

\begin{tabular}{|c|c|c|c|c|c|c|c|c|c|}
\hline \multirow[b]{2}{*}{ Province } & \multirow[b]{2}{*}{ Pig } & \multicolumn{2}{|l|}{ Sample } & \multicolumn{2}{|l|}{ PCR } & \multicolumn{2}{|l|}{$\mathrm{Vl}$} & \multicolumn{2}{|c|}{ Bacteriology } \\
\hline & & ID & Type & PRRS & PCV-2 & PBMC & MARC-145 & S. zooep ${ }^{a}$ & E. colib \\
\hline \multirow[t]{4}{*}{ Quang Nam } & 1 & 07QN-1 & $\mathrm{Sp}^{c} \& \mathrm{Lg}$ & + & + & + & - & + & + \\
\hline & 2 & 07QN-2 & Lg & - & + & - & - & + & + \\
\hline & & & $S p$ & + & + & + & - & + & + \\
\hline & 3 & 07QN-3 & Sp \& Lg & + & + & + & - & + & + \\
\hline Thai Binh & 4 & 07TB & LN \& Lg & + & - & + & + & NT & NT \\
\hline Bac Giang & 5 & 07BG & LN \& Lg & + & - & + & + & NT & NT \\
\hline Hung Yen & 6 & 07HY & LN \& Lg & + & - & + & + & NT & NT \\
\hline Ha Noi & 7 & 07HN & LN \& Lg & + & - & + & + & NT & NT \\
\hline
\end{tabular}

Samples positive for ${ }^{a}$ Streptococcus equi subspecies zooepidemicus, ${ }^{b}$ non-hemolytic Escherichia coli and ' $S$ treptococcus suis. Samples not tested (NT). Sample types are defined as Sp, spleen; Lg, lung; LN, lymph node; PCV, porcine circovirus; PRRSV, porcine reproductive and respiratory syndrome virus. 
98.6-99.6\% identity to Chinese strain HUN4, in contrast to their low percentage of identity to VR-2332 (77\%) and MN184 (71\%).

Comparison of predicted amino acid (aa) sequence in the nsp2 region revealed a range of $95.7-99.4 \%$ identity between the Vietnamese isolates and HUN4. This wide range of identity could be attributed to the variations within the Vietnamese PRRSV isolates. The nsp2 amino acid identity with North American strains was even lower, only $68-69 \%$ and $58-59 \%$ identity to VR-2332 and MN184, respectively. For the GP5 protein, all Vietnamese isolates were $99.5-100 \%$ identical to the Chinese strain HUN4, whereas all isolates were $88-89 \%$ identical in amino acid sequence to the prototype North American (Type 2) strain VR-2332 and $86-87 \%$ identical to strain MN184. Phylogenetic analyses of nsp2 and ORF-5 was

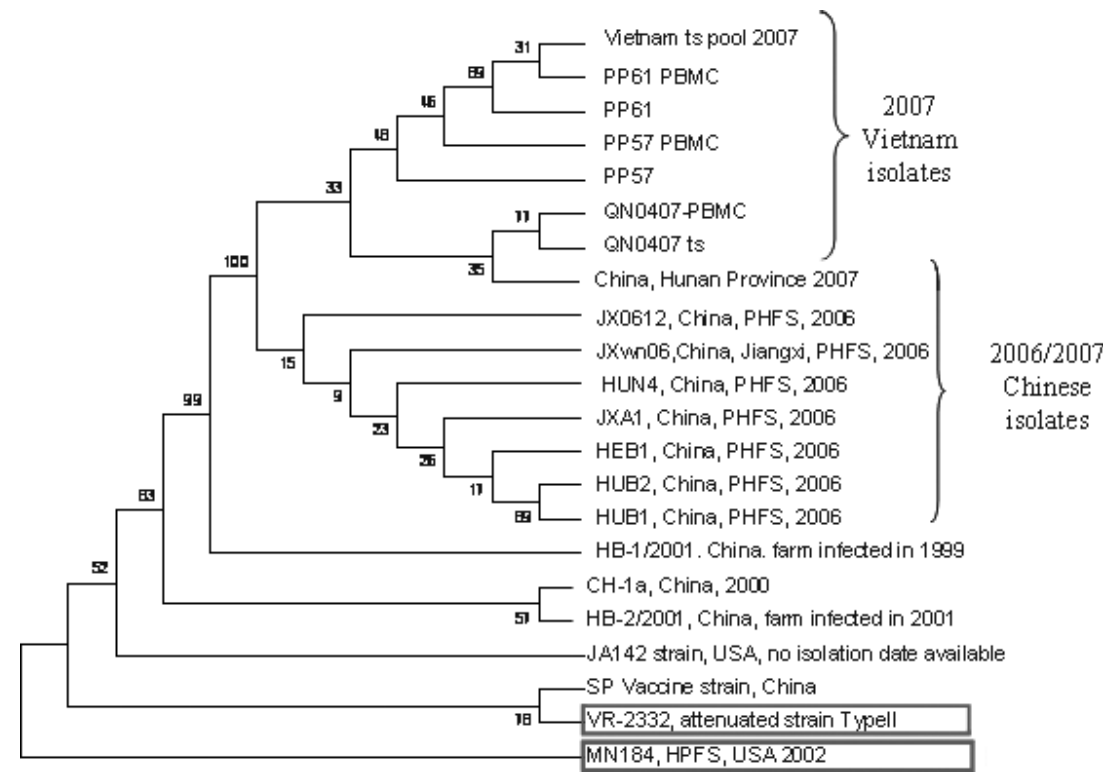

Fig. 3. PRRSV phylogeny of ORF- 5 nucleotide sequences. ORF- 5 unrooted tree by neighbour-joining method with bootstrapping. ts: sequence obtained from original tissue samples; PP: Pig Passage; PBMC/p1: sequence obtained from same tissue samples after 1 passage in PBMCs; Boxes: indicate the prototype PRRSV (VR-2332) and highly virulent (MN184).

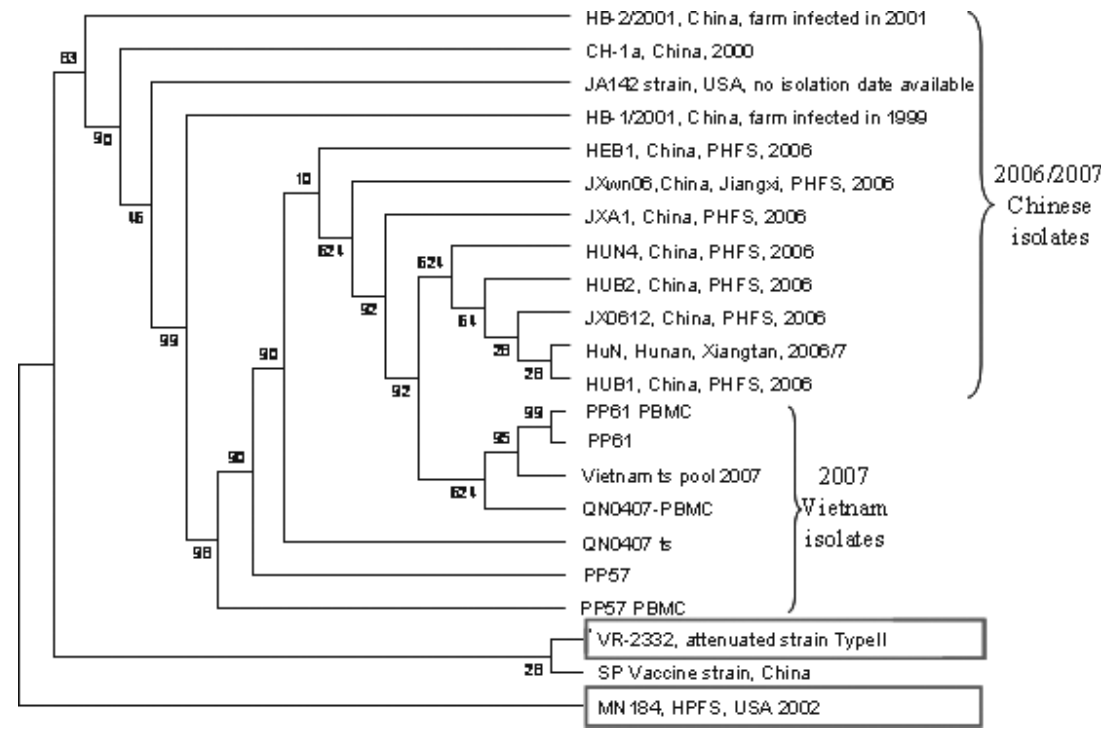

Fig. 4. PRRSV phylogeny of nsp2 nucleotide sequences Nsp2 un-rooted tree neighbour-joining method with bootstrapping. ts: sequence obtained from original tissue samples; PP: Pig Passage; PBMC/p1: sequence obtained from same tissue samples after 1 passage in PBMCs; Boxes: indicate the prototype PRRSV, attenuated (VR-2332) and highly virulent (MN184). 
PRRSV Tissue homogenate inoculated

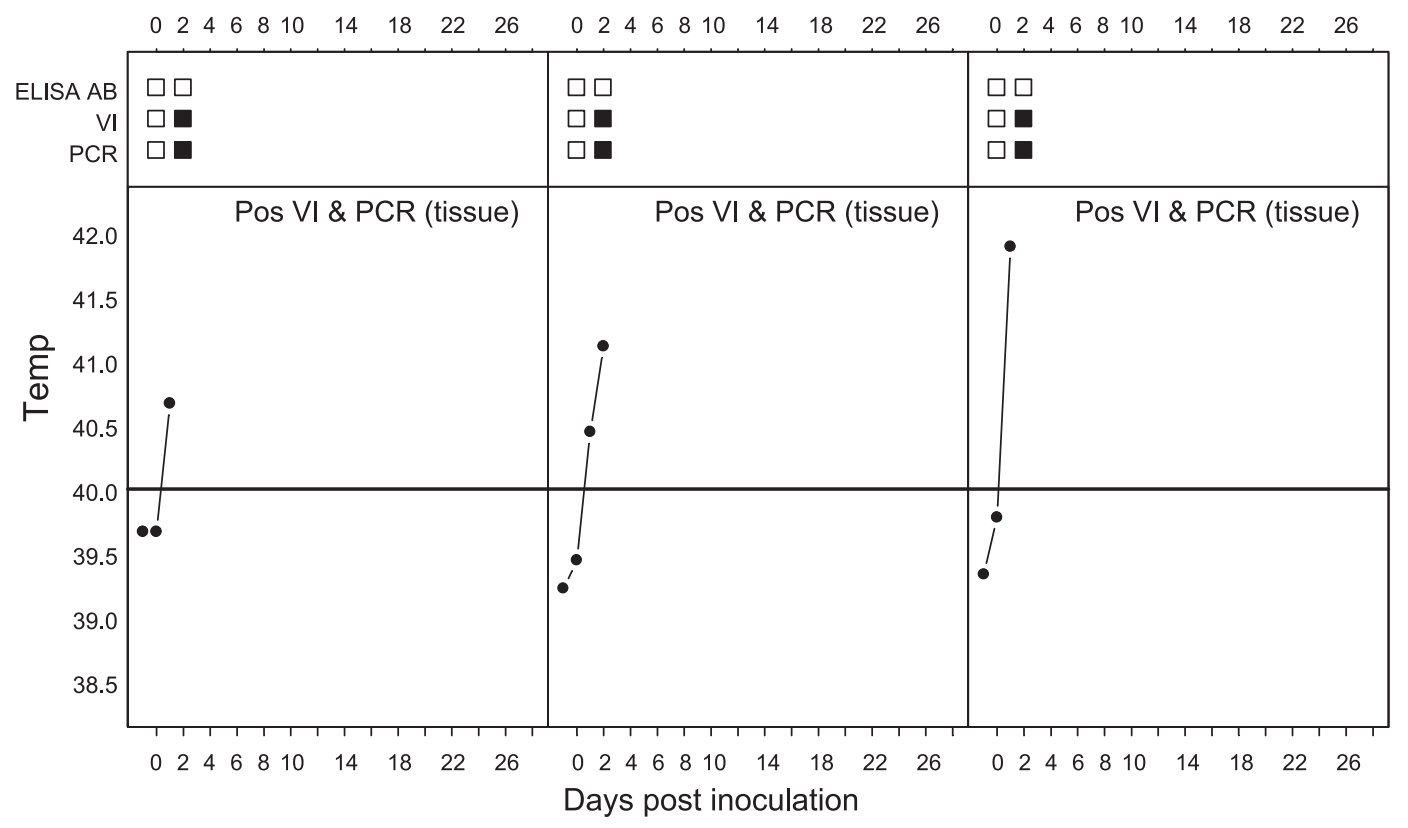

PRRSV Tissue homogenate

contact

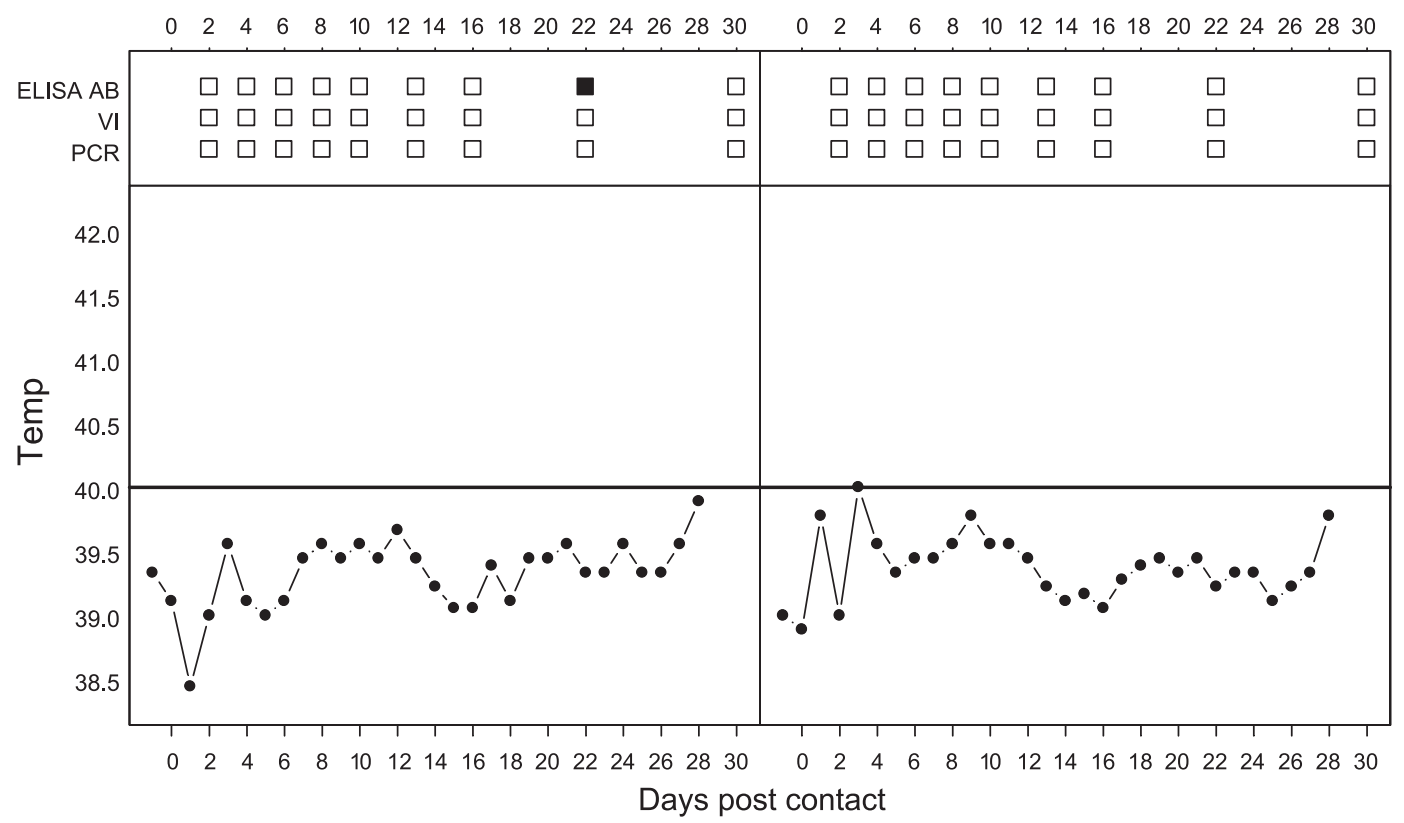

Fig. 5. Body temperature, virus isolation, $P C R$, and serology results on pigs inoculated with or contact exposed to either tissue homogenate (Group 1) or cultured porcine reproductive and respiratory syndrome virus (PRRSV) (Group 2). Each box represents a different animal. Three inoculated and two contact pigs were used each for PRRSV tissue homogenate group (group 1) and tissue culture (group 2). Days post-inoculation or post contact are represented on the horizontal $X$-axis for each animal. Body temperature was measured in Centigrade degrees shown on the $Y$-axis. The bold horizontal line at $40.0 \mathrm{C}$ represents the highest temperature considered nonfebrile, after which is considered febrile. Antibody ELISA (ELISA AB) positive serum is represented by a filled square and negative serum is represented by an open square opposite the AB ELISA designation. Virus isolation $(\mathrm{VI})$ and RT-PCR (PCR) were performed on serum. An open box represents negative results and a filled box represents positive for VI or PCR results opposite the VI or PCR designations. Spleen, lung, and lymph nodes collected at necropsy that were positive for PRRSV by PCR and VI are indicated as positive by a text note in each box corresponding to a positive animal. 
Group 2

\section{PRRSV Tissue culture} inoculated

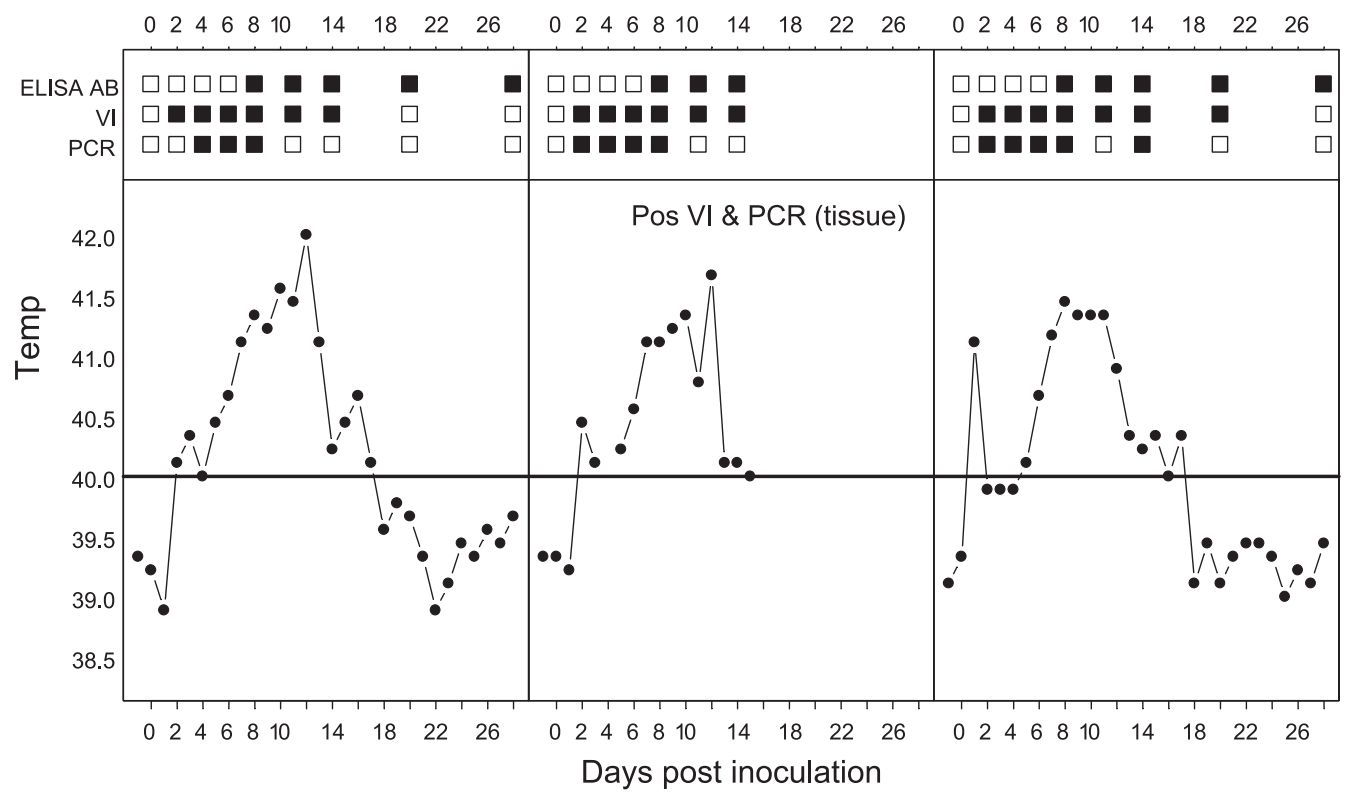

PRRSV Tissue culture contact

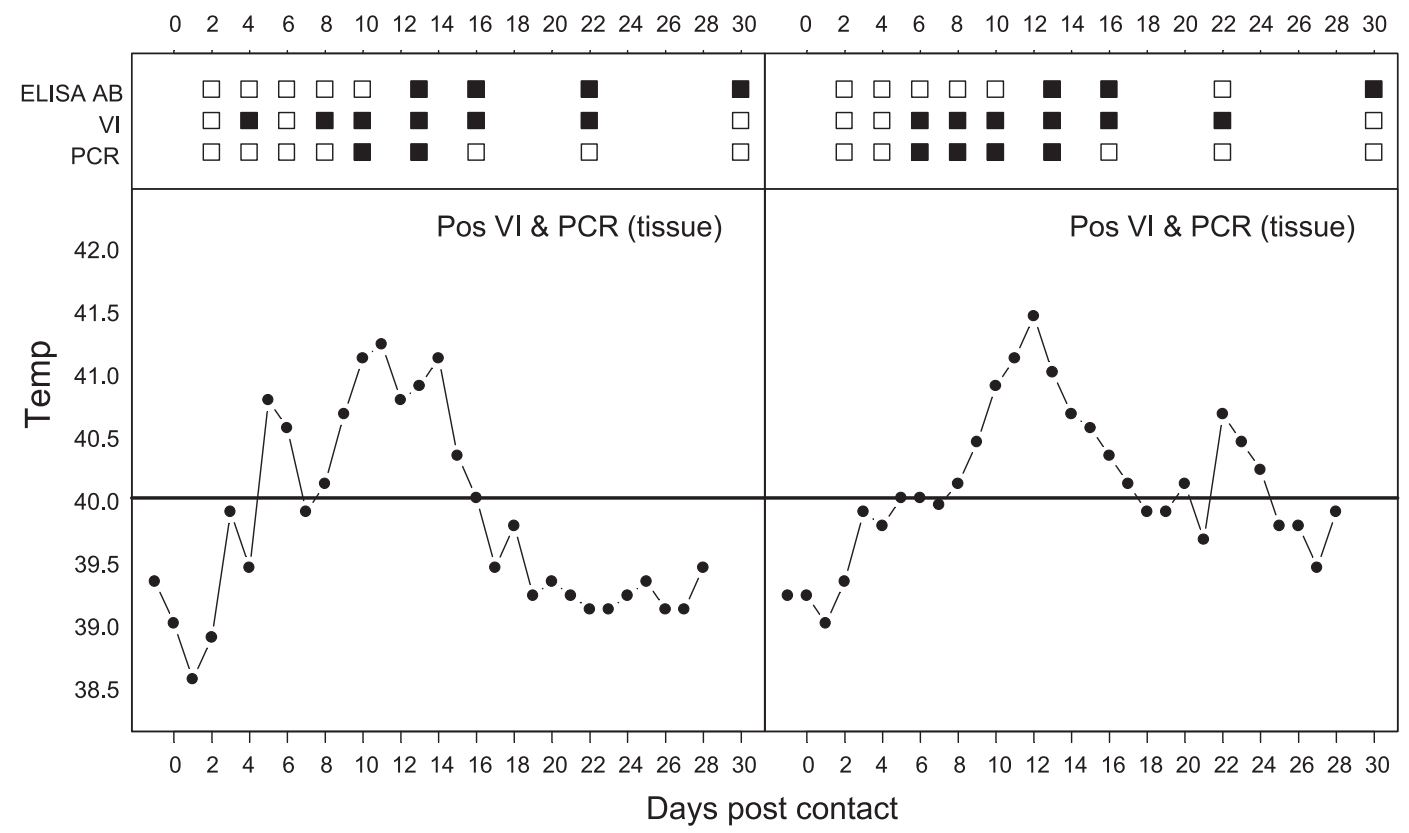

Fig. 5. (Continued).

completed using both Neighbour-Joining and UPGMA algorithms, each with percent identity or BLOSUM62, to confirm the relationships between the different viruses analysed (Figs 3 and 4).
Animal inoculation

The three pigs that received the tissue homogenate (group one) developed high fever $\left(40.6-41.7^{\circ} \mathrm{C}\right)$ within $24-72 \mathrm{~h}$, 
septicaemia and acute death within 48-72 h after inoculation (Fig. 5). Gross necropsy findings were similar in all three animals and consisted mainly of severe fibrinous peritonitis, pleuritis and pleural effusions. Histopathology showed severe fibrinosuppurative pleuritis. Additionally, necrosuppurative lymphadenitis was observed in two pigs. Streptococcus equi subspecies zooepidemicus was cultured, and PPRSV was reisolated, detected by RT-PCR, and sequenced from lungs and spleens. The two contact pigs showed no clinical signs throughout the experiment as their exposure to the inoculated pig dying acutely was $<24 \mathrm{~h}$. Necropsy findings of the contact pigs were not significant, and histopathology showed mild lymphoid follicular hyperplasia of the mandibular and thoracic lymph nodes. PRRSV was only isolated and detected by RT-PCR from lung and spleen of three inoculated pigs.

The three pigs that received the PRRSV in PBMC culture (group two) had fever starting $2 \mathrm{dpi}$ and their two contact pigs at 5-8 dpc. Body temperature peaked at 7-
$10 \mathrm{dpi} / \mathrm{dpc}\left(40.6-41.1^{\circ} \mathrm{C}\right)$ and persisted for 1 week before starting to decline (Fig. 5). Pigs were depressed, had low appetite, and a rough hair coat. One of the tissue culture inoculated pigs in group two was euthanized (15 dpi) because of swollen joints and loss of mobility. Upon necropsy, this pig had bronchopneumonia, fibrinous pericarditis with pericardial effusions and polyarthritis. Histopathology showed myocarditis, perisplenitis, suppurative lymphadenitis, suppurative pneumonia with intralesional bacteria and severe meningoencephalitis. The remaining pigs in group two were euthanized at $28 \mathrm{dpi} /$ $26 \mathrm{dpc}$, and the gross necropsy findings were variable. All animals had fibrinous peritonitis ranging from mild to severe with peritoneal effusions. In addition, inoculated and contact pigs from group two had severe, chronic pericarditis, fibrinous pleuritis and polyarthritis (Fig. 6). Histopathological examination confirmed gross findings of multifocal interstitial pneumonia, lymphoid hyperplasia in some animals (Fig. 6), and additionally pericarditis, peritonitis and meningoencephalitis (Fig. 6). PRRSV was
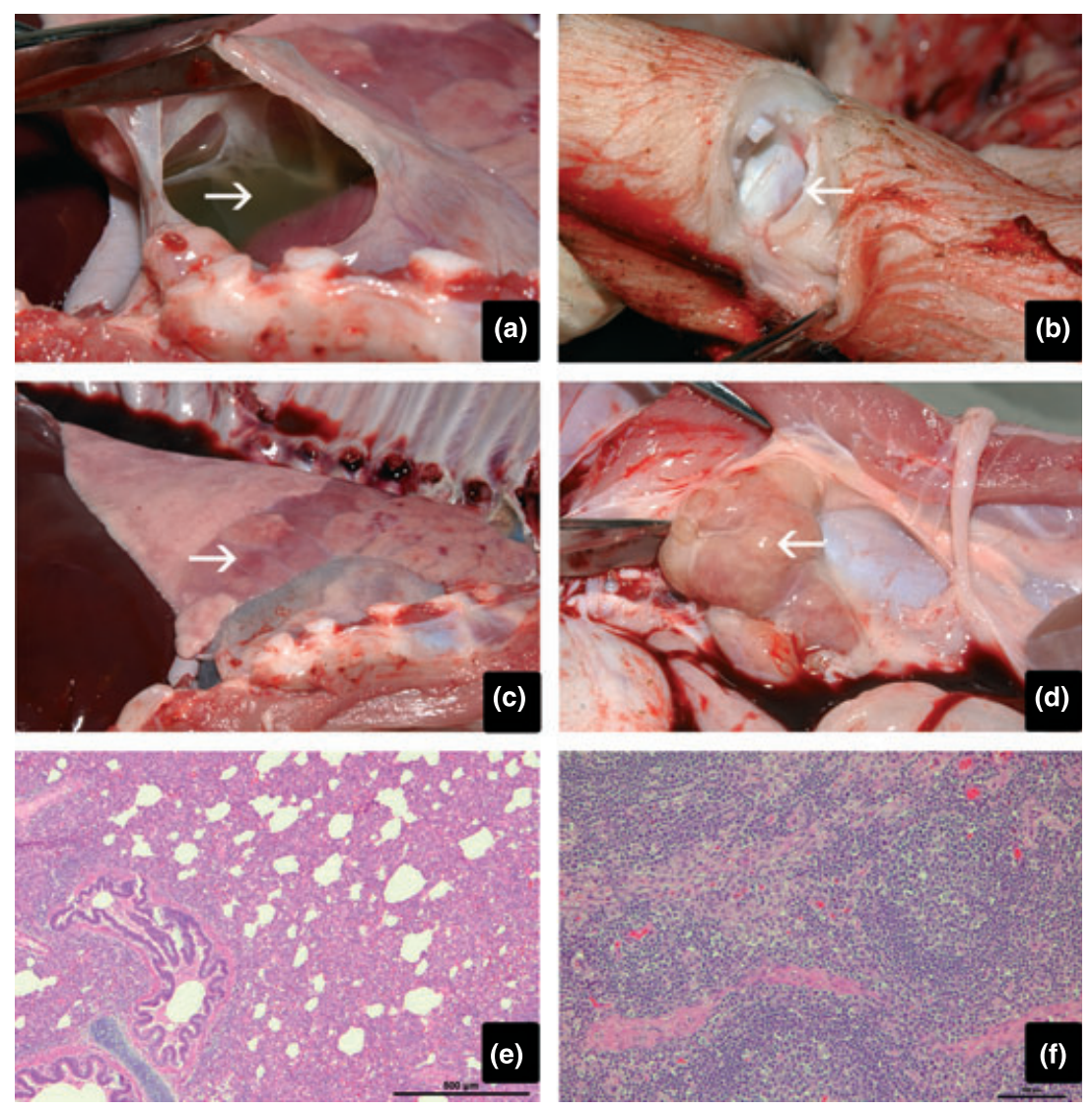

Fig. 6. Gross and histopathological lesions in pigs inoculated with tissue culture PRRSV (group 2). (a) Fibrinous pericarditis and pericardial effusions (arrow), (b) Arthritis (arrow), (c) Interstitial pneumonia (arrow) and (d) lymphoid hyperplasia (arrow). Photomicrographs of interstitial pneumonia showing thickening of the alveolar walls and type II cell hyperplasia (e), and marked follicular lymphoid hyperplasia of the lymph node (f). Pericarditis and arthritis are likely due to secondary bacterial infection. 
isolated from sera of inoculated and contact pigs starting at $2 \mathrm{dpi} / 2-6 \mathrm{dpc}$, and PRRS antibody was first detected at $8 \mathrm{dpi} / 12 \mathrm{dpc}$ (Fig. 5). PRRSV was isolated and detected by RT-PCR from lung and spleen of one of the inoculated pigs and the two contact pigs. The sham-inoculated control pigs (group 3) showed no clinical signs throughout the experiment and tested negative for PRRSV and antibody (data not shown).

\section{Discussion}

In this study, a diagnostic investigation was conducted on disease outbreaks causing respiratory distress, which affected thousands of swine in Vietnam in 2007. Similar epidemics of severe swine disease, referred to as Porcine High Fever Disease (PHFD), were reported in Southeast Asia in 2006 (Tian et al., 2007a; Zhou et al., 2008). Investigations into these cases consistently identified PRRSV, and thus this virus has been implicated as the primary cause of these epidemics. Here we present data of PRRSV isolated from specimens submitted from northern, central and southern provinces of Vietnam with sequence analysis similar to the Chinese isolates from 2006 including the identical deletion of nsp2 region. Deletions in the nsp-2 region, and the $5^{\prime}$ and $3^{\prime}$ UTR of the PRRSV sequence have been correlated with the high pathogenicity of these infections (Feng et al., 2008; An et al., 2010). Co-infection with E. coli, Streptococcus equi subspecies zooepidemicus, Streptococcus suis and/or PCV-2 was confirmed in a number of samples from the same or different pigs. As strains of PRRSV are known to vary in pathogenicity (Drew, 2000), an animal study was conducted on the Vietnamese PRRSV strain to determine its degree of pathogenicity in the absence of other agents. The inoculated pigs (except for the ones which died acutely) had persistent high fever for 2 weeks, mild to severe respiratory distress, seroconverted within $8 \mathrm{dpi}$, and the virus was reisolated from serum, lungs and spleen in most animals The duration of viraemia and the persistence of the virus in tissues past the viremic stage were similar to those reported by Christopher-Hennings et al., 2001. Our findings differ from the previous reports (Tian et al., 2007a; Tong et al., 2007) where the Chinese PRRSV strain was characterized as a highly virulent variant causing high fever and up to $100 \%$ mortality within $6-10$ days post-exposure; however, the breed of pigs used in those studies was not specified and may have played a role in the susceptibility to infection.

Most pigs in this study showed evidence of secondary bacterial infection manifested by peritonitis, pleuritis and pericarditis, which may indicate increased susceptibility or immunosuppression. Immunosuppresion was often associated with PRRS, and several studies were undertaken to study the mechanism of immunosuppression in
PRRS (Drew, 2000). While there is some field evidence of immunosuppression of pigs following PRRSV infection, the experimental evidence is somewhat ambiguous. It is likely that any effects are because of a transient deterioration of local lung cellular defence where the virus tropism is for alveolar macrophages, which is difficult to reproduce experimentally (Pol and Wagenaar, 1992, Voicu et al., 1994). It has also been reported (Gomez-Laguna et al., 2010) that PRRSV modulate the immune response by upregulation of IL-10, which may in turn reduce the expression of cytokines involved in viral clearance. It is important to note that pigs inoculated with tissue homogenates from the diagnostic submission samples died acutely with septicaemia with no evidence of toxicity as determined by histopathological examination of tissues. Additionally, when filtered tissue homogenate was inoculated into two naïve pigs, no clinical signs of toxicity were noted (data not shown).

In this study, pigs did not show significant decrease in total WBC count throughout the experiment (data not shown). A recent report (Shi et al., 2008) showed that the total WBC count was significantly lower in pigs inoculated with HB-2 strain than the control group at 7 dpi but became significantly higher than the control at 0,14 and $28 \mathrm{dpi}$. To reproduce similar disease as reported in the outbreaks, experimental group one was inoculated with the original tissue homogenates neither pre-treated with antibiotics nor filtered, so that any agent present might have the opportunity to exacerbate disease. Inoculated pigs died acutely within $72 \mathrm{~h}$ with a septicaemia.

PRRSV and bacterial infection were detected in infected animals confirming earlier observations that PRRSV and other agents were involved in these epidemics. It is likely Streptococcus suis, and E. coli, or other agents may have played a role in increasing the severity of the outbreak in Vietnam, as previously reported in other PRRSV infections (Thanawongnuwech et al., 2000a; Feng et al., 2001; Rovira et al., 2002).

In 2001, many virulent isolates of PRRSV from Minnesota were genetically closely related to the Canadian isolates of the 1990s (Mardassi et al., 1994) and Minnesota isolates of 1998 (Wesley et al., 1998). Isolates with similar ORF-5 genomic patterns to the MN184 have been reported in Iowa, Wisconsin, South Dakota, Kansas, Missouri, Illinois, Nebraska, Kentucky, Oklahoma and Wyoming but showed variable levels of pathogenicity suggesting no direct correlation between severity of disease and genetic makeup (Han et al., 2006b). In our experiment, partial genome sequencing of the PRRSV reisolated from blood samples and tissues of the inoculated pigs confirmed the presence of the exact same GP5 mutations and nsp2 deletions found in the field samples. Transmission EM examination of tissue collected from inoculated 
pigs and in cell culture passage showed typical single and double membrane profiles described previously (Snijder, 1998; Tian et al., 2007a) with the extracellular accumulation of 70-nm particles found with EM analysis of PRRSV exposed cells in vitro and in vivo (Dea et al., 1995; Balasuriya et al., 2004). Therefore, our results suggest that the PRRSV emerging in Vietnam 2007, despite the presence of the characteristic nsp2 deletions previously described as a marker of virulence and high pathogenicity for pigs, is not solely responsible for the high death rate that characterizes these epidemics.

Phylogenetic analysis revealed that the Vietnamese isolates belong to the North American genotype (Type 2) PRRSV and are closely related to Chinese strains from 2006 to 2007 (HUB1, HuN, JX0612 and others) with two nsp2 deletions when compared to the prototype strain VR-2332. The nsp2 of PRRSV is a multidomain protein that has been shown to undergo remarkable genetic variation. From its three major domains (den Boon et al., 1995; Han et al., 2006a, 2007), nsp2 is the most divergent protein between PRRSV types 1 and 2 (Allende et al., 1999; Nelsen et al., 1999) and also between the pathogenic PRRSV 16244B and an attenuated vaccine and its parental strain VR2332 (Allende et al., 1999, 2000; Nelsen et al., 1999). A large amount of data supports the theory that the middle section of the nsp2 protein is highly susceptible to mutation and tolerant to insertions and deletions, regardless of the pathogenic phenotype of the isolates (Allende et al., 1999, 2000; Nelsen et al., 1999; Shen et al., 2000; Fang et al., 2004, 2006; Gao et al., 2004; Ropp et al., 2004; Diao et al., 2005; Han et al., 2006b, 2007; Kim et al., 2007; Ran et al., 2008). In fact, reverse genetics experiments have mapped several non-essential viral replication regions in nsp2, including a large deletion of 402 nucleotides in the middle region of the gene (Han et al., 2007). These reports and our data contrast with the suggestion that the nsp2 deletions found in the atypical PRRS outbreak in 2006 in China could be correlated with a highly virulent phenotype (Li et al., 2007, 2008; Tian et al., 2007a,b; Zhou et al., 2008).

Co-circulation of other pig disease causing agents with PRRSV has been noted by other authors. PCV-2 co-infection with PRRSV was detected in some of these samples, and CSFV was detected in addition to PRRSV from samples received in a subsequent diagnostic submission to FADDL from other locations in Vietnam. As final evidence, in agreement with our conclusions, a recently published reverse genetics experiment has demonstrated that there was no direct correlation between the 30 aa deletion in nsp2 of the Chinese PRRSV and virulence (Zhou et al., 2009). Additional studies are needed to determine and compare the pathogenicity of the Vietnamese PRRS virus to prototype PRRSV type 1 strains.

\section{Acknowledgements}

We thank the contributions made to the technical analysis provided by our colleagues at FADDL, to Dr Guillermo Risatti (University of Connecticut) for providing primers and advice for RT-PCR and sequencing techniques, to Dr Sabrina Swenson for technical revision to the manuscript, to the Animal Resource Unit of PIADC: Mr Jeff Babcock, John Brown, Donald Hermance and Ralph Soto, and to Mrs Kathy Apicelli and Mr Ethan Macnow for visual aids support.

\section{References}

Allende, R., T. L. Lewis, Z. Lu, D. L. Rock, G. F. Kutish, A. Ali, A. R. Doster, and F. A. Osorio, 1999: North American and European porcine reproductive and respiratory syndrome viruses differ in non-structural protein coding regions. J. Gen. Virol. 80(Pt 2), 307-315.

Allende, R., G. F. Kutish, W. Laegreid, Z. Lu, T. L. Lewis, D. L. Rock, J. Friesen, J. A. Galeota, A. R. Doster, and F. A. Osorio, 2000: Mutations in the genome of porcine reproductive and respiratory syndrome virus responsible for the attenuation phenotype. Arch. Virol. 145, 11491161.

An, T. Q., Z. J. Tian, Y. Xiao, R. Li, J. M. Peng, T. C. Wei, Y. Zhang, Y. J. Zhou, and G. Z. Tong, 2010: Origin of highly pathogenic porcine reproductive and respiratory syndrome virus, China. Emerg. Infect. Dis. 16, 365-367.

Balasuriya, U. B., J. C. Dobbe, H. W. Heidner, V. L. Smalley, A. Navarrette, E. J. Snijder, and N. J. MacLachlan, 2004: Characterization of the neutralization determinants of equine arteritis virus using recombinant chimeric viruses and site-specific mutagenesis of an infectious cDNA clone. Virology 321, 235-246.

Batista, L., S. A. Dee, K. D. Rossow, J. Deen, and C. Pijoan, 2002: Assessing the duration of persistence and shedding of porcine reproductive and respiratory syndrome virus in a large population of breeding-age gilts. Can. J. Vet. Res. 66, 196-200.

Benson, D. A., I. Karsch-Mizrachi, D. J. Lipman, J. Ostell, and D. L. Wheeler, 2008: GenBank. Nucleic Acids Res. 36, D25D30.

den Boon, J. A., K. S. Faaberg, J. J. Meulenberg, A. L. Wassenaar, P. G. Plagemann, A. E. Gorbalenya, and E. J. Snijder, 1995: Processing and evolution of the N-terminal region of the arterivirus replicase ORF1a protein: identification of two papainlike cystein proteases. J. Virol. 69, 4500-4505.

Callahan, J. D., F. Brown, F. A. Osorio, J. H. Sur, E. Kramer, G. W. Long, J. Lubroth, S. J. Ellis, K. S. Shoulars, K. L. Gaffney, D. L. Rock, and W. M. Nelson, 2002: Use of a portable real-time reverse transcriptase-polymerase chain reaction assay for rapid detection of foot-and-mouth disease virus. J. Am. Vet. Med. Assoc. 220, 1636-1642. 
Callens, M., and K. De Clercq, 1999: Highly sensitive detection of swine vesicular disease virus based on a single tube RT-PCR system and DIG-ELISA detection. J. Virol. Methods 77, 87-99.

Cavanagh, D., 1997: Nidovirales: a new order comprising Coronaviridae and Arteriviridae. Arch. Virol. 142, 629-633.

Christopher-Hennings, J., L. D. Holler, D. A. Benfield, and E. A. Nelson, 2001: Detection and duration of porcine reproductive and respiratory syndrome virus in semen, serum, peripheral blood mononuclear cells, and tissues from Yorkshire, Hampshire, and Landrace boars. J. Vet. Diagn. Invest. 13, 133-142.

Collins, J., D. A. Benfield, W. T. Christianson, L. Harris, J. C. Hennings, D. P. Shaw, S. M. Goyal, S. McCullough, R. B. Morrison, H. S. Joo, D. Gorcyca, and D. Chladek, 1992: Isolation of swine infertility and respiratory syndrome virus (isolate ATCC VR-2332) in North America and experimental reproduction of the disease in gnotobiotic pigs. J. Vet. Diagn. Invest. 4, 117-126.

Dea, S., N. Sawyer, R. Alain, and R. Athanassious, 1995: Ultrastructural characteristics and morphogenesis of porcine reproductive and respiratory syndrome virus propagated in the highly permissive MARC-145 cell clone. Adv. Exp. Med. Biol. 380, 95-98.

Diao, Y. X., J. B. Ding, S. J. Jiang, Z. Z. Cui, and B. L. Chen, 2005: PCR detection of PCV-2 and PRRSV in porcine pleuropneumonia samples. Wei Sheng Wu Xue Bao 45, 397-400.

Drew, T.W., 2000: A review of evidence for immunosuppression due to porcine reproductive and respiratory syndrome virus. Vet. Rec. 31, 27-39.

Fang, Y., D. Y. Kim, S. Ropp, P. Steen, J. ChristopherHennings, E. A. Nelson, and R. R. Rowland, 2004: Heterogeneity in Nsp2 of European-like porcine reproductive and respiratory syndrome viruses isolated in the United States. Virus Res. 100, 229-235.

Fang, Y., R. R. Rowland, M. Roof, J. K. Lunney, J. Christopher-Hennings, and E. A. Nelson, 2006: A full-length cDNA infectious clone of North American type 1 porcine reproductive and respiratory syndrome virus: expression of green fluorescent protein in the Nsp2 region. J. Virol. 80, 11447-11455.

Fenaux, M., P. Halbur, M. Gill, T. E. Toth, and X. J. Meng, 2000: Genetic characterization of type 2 porcine circovirus (PCV-2) from pigs with postweaning multisystemic wasting syndrome in different geographic regions of North America and development of a differential PCR-restriction fragment length polymorphism assay to detect and differentiate between infections with PCV-1 and PCV-2. J. Clin. Microbiol. 38, 2494-2503.

Feng, W., S. M. Laster, M. Tompkins, T. Brown, J. S. Xu, C. Altier, W. Gomez, D. Benfield, and M. B. McCaw, 2001: In utero infection by porcine reproductive and respiratory syndrome virus is sufficient to increase susceptibility of piglets to challenge by Streptococcus suis type II. J. Virol. 75, 4889-4895.

Feng, Y., T. Zhao, T. Nguyen, K. Inui, Y. Ma, T. H. Nguyen, V. C. Nguyen, D. Liu, Q. A. Bui, L. T. Thanh, C. Wang,

K. Tian, and G. Gao, 2008: Porcine respiratory and reproductive syndrome virus variants, Vietnam and China 2007. Emerg. Infect. Dis. 14, 1774-1776.

Gao, Z. Q., X. Guo, and H. C. Yang, 2004: Genomic characterization of two Chinese isolates of porcine respiratory and reproductive syndrome virus. Arch. Virol. 149, 1341-1351.

Gomez-Laguna, J., F. J. Salguero, I. Barranco, F. J. Pallares, I. M. Rodriguez-Gomez, A. Bernabe, and L. Carrasco, 2010: Cytokine expression by macrophages in the lung of pigs infected with porcine reproductive and respiratory syndrome virus. J. Comp. Pathol. 142, 51-60.

Han, J., K. M. Burkhart, E. M. Vaughn, M. B. Roof, and K. S. Faaberg, 2006a: Replication and expression analysis of PRRSV defective RNA. Adv. Exp. Med. Biol. 581, 445-448.

Han, J., Y. Wang, and K. S. Faaberg, 2006b: Complete genome analysis of RFLP 184 isolates of porcine reproductive and respiratory syndrome virus. Virus Res. 122, 175-182.

Han, J., G. Liu, Y. Wang, and K. S. Faaberg, 2007: Identification of nonessential regions of the nsp2 replicase protein of porcine reproductive and respiratory syndrome virus strain VR-2332 for replication in cell culture. J. Virol. 81, 98789890.

Kim, D. Y., J. G. Calvert, K. O. Chang, K. Horlen, M. Kerrigan, and R. R. Rowland, 2007: Expression and stability of foreign tags inserted into nsp2 of porcine reproductive and respiratory syndrome virus (PRRSV). Virus Res. 128, 106-114.

Krumbholz, A., R. Wurm, O. Scheck, E. Birch-Hirschfeld, R. Egerer, A. Henke, P. Wutzler, and R. Zell, 2003: Detection of porcine teschoviruses and enteroviruses by LightCycler real-time PCR. J. Virol. Methods 113, 51-63.

Li, Y., X. Wang, K. Bo, X. Wang, B. Tang, B. Yang, W. Jiang, and P. Jiang, 2007: Emergence of a highly pathogenic porcine reproductive and respiratory syndrome virus in the Mid-Eastern region of China. Vet. J. 174, 577-584.

Li, Y., X. Wang, P. Jiang, W. Chen, and X. Wang, 2008: Genetic analysis of two porcine reproductive and respiratory syndrome viruses with different virulence isolated in China. Arch. Virol. 153, 1877-1884.

Mardassi, H., S. Mounir, and S. Dea, 1994: Identification of major differences in the nucleocapsid protein genes of a Quebec strain and European strains of porcine reproductive and respiratory syndrome virus. J. Gen. Virol. 75(Pt 3), 681-685.

Meredith, M., 1993: Porcine Reproductive and Respiratory Syndrome, 7th edn. University of Cambridge Press, Cambridge.

Meulenberg, J. J., M. M. Hulst, E. J. de Meijer, P. L. Moonen, A. den Besten, E. P. de Kluyver, G. Wensvoort, and R. J. Moormann, 1993: Lelystad virus, the causative agent of 
porcine epidemic abortion and respiratory syndrome (PEARS), is related to LDV and EAV. Virology 192, 62-72.

Murtaugh, M., J. E. Collins, and K. D. Rossow, 1993: Porcine Respiratory and Reproductive Syndrome. A.D. leman Swine Conference Proceedings. University of Minnesota, Minneapolis, MN, 43-53.

Nelsen, C. J., M. P. Murtaugh, and K. S. Faaberg, 1999: Porcine reproductive and respiratory syndrome virus comparison: divergent evolution on two continents. J. Virol. 73, 270-280.

Nelson, E. A., J. Christopher-Hennings, T. Drew, G. Wensvoort, J. E. Collins, and D. A. Benfield, 1993: Differentiation of U.S. and European isolates of porcine reproductive and respiratory syndrome virus by monoclonal antibodies. J. Clin. Microbiol. 31, 3184-3189.

Pol, J., and F. Wagenaar, 1992: Morphogenesis of Lelystad virus in porcine alveolar macrophages. Am. Assoc. of swine practitioners Newsletter 4, 29.

Ran, Z. G., X. Y. Chen, X. Guo, X. N. Ge, K. J. Yoon, and H. C. Yang, 2008: Recovery of viable porcine reproductive and respiratory syndrome virus from an infectious clone containing a partial deletion within the Nsp2-encoding region. Arch. Virol. 153, 899-907.

Risatti, G. R., J. D. Callahan, W. M. Nelson, and M. V. Borca, 2003: Rapid detection of classical swine fever virus by a portable real-time reverse transcriptase PCR assay. J. Clin. Microbiol. 41, 500-505.

Ropp, S. L., C. E. Wees, Y. Fang, E. A. Nelson, K. D. Rossow, M. Bien, B. Arndt, S. Preszler, P. Steen, J. ChristopherHennings, J. E. Collins, D. A. Benfield, and K. S. Faaberg, 2004: Characterization of emerging European-like porcine reproductive and respiratory syndrome virus isolates in the United States. J. Virol. 78, 3684-3703.

Rovira, A., M. Balasch, J. Segales, L. Garcia, J. Plana-Duran, C. Rosell, H. Ellerbrok, A. Mankertz, and M. Domingo, 2002: Experimental inoculation of conventional pigs with porcine reproductive and respiratory syndrome virus and porcine circovirus 2. J. Virol. 76, 3232-3239.

Shen, S., J. Kwang, W. Liu, and D. X. Liu, 2000: Determination of the complete nucleotide sequence of a vaccine strain of porcine reproductive and respiratory syndrome virus and identification of the Nsp2 gene with a unique insertion. Arch. Virol. 145, 871-883.

Shi, K., H. Li, X. Guo, X. Ge, H. Jia, S. Zheng, and H. Yang, 2008: Changes in peripheral blood leukocyte subpopulations in piglets co-infected experimentally with porcine reproductive and respiratory syndrome virus and porcine circovirus type 2. Vet. Microbiol. 129, 367-377.

Snijder, E. J. M. J., 1998: The molecular biology of arteriviruses. J. Gen. Virol. 79, 961-979.

Thanawongnuwech, R., G. B. Brown, P. G. Halbur, J. A. Roth, R. L. Royer, and B. J. Thacker, 2000a: Pathogenesis of porcine reproductive and respiratory syndrome virus-induced increase in susceptibility to Streptococcus suis infection. Vet. Pathol. 37, 143-152.
Tian, K., X. Yu, T. Zhao, Y. Feng, Z. Cao, C. Wang, Y. Hu, X. Chen, D. Hu, X. Tian, D. Liu, S. Zhang, X. Deng, Y. Ding, L. Yang, Y. Zhang, H. Xiao, M. Qiao, B. Wang, L. Hou, X. Wang, X. Yang, L. Kang, M. Sun, P. Jin, S. Wang, Y. Kitamura, J. Yan, and G. F. Gao, 2007a: Emergence of fatal PRRSV variants: unparalleled outbreaks of atypical PRRS in China and molecular dissection of the unique hallmark. PLoS ONE 2, e526.

Tian, X., Y. Feng, T. Zhao, H. Peng, J. Yan, J. Qi, F. Jiang, K. Tian, and F. Gao, 2007b: Molecular cloning, expression, purification and crystallographic analysis of PRRSV 3CL protease. Acta Crystallogr 63, 720-722.

Tong, G. Z., Y. J. Zhou, X. F. Hao, Z. J. Tian, T. Q. An, and H. J. Qiu, 2007: Highly pathogenic porcine reproductive and respiratory syndrome, China. Emerg. Infect. Dis. 13, 1434-1436.

Voicu, I. L., A. Silim, M. Morin, and M. A. Elazhary, 1994: Interaction of porcine reproductive and respiratory syndrome virus with swine monocytes. Vet. Rec. 134, 422423.

van Vugt, J. J., T. Storgaard, M. B. Oleksiewicz, and A. Botner, 2001: High frequency RNA recombination in porcine reproductive and respiratory syndrome virus occurs preferentially between parental sequences with high similarity. J. Gen. Virol. 82, 2615-2620.

Wensvoort, G., 1993: Lelystad virus and the porcine epidemic abortion and respiratory syndrome. Vet. Res. 24, 117-124.

Wensvoort, G., E. P. de Kluyver, J. M. Pol, F. Wagenaar, R. J. Moormann, M. M. Hulst, R. Bloemraad, A. den Besten, T. Zetstra, and C. Terpstra, 1992: Lelystad virus, the cause of porcine epidemic abortion and respiratory syndrome: a review of mystery swine disease research at Lelystad. Vet. Microbiol. 33, 185193.

Wesley, R. D., W. L. Mengeling, K. M. Lager, D. F. Clouser, J. G. Landgraf, and M. L. Frey, 1998: Differentiation of a porcine reproductive and respiratory syndrome virus vaccine strain from North American field strains by restriction fragment length polymorphism analysis of ORF 5. J. Vet. Diagn. Invest. 10, 140-144.

Yuan, S., C. J. Nelsen, M. P. Murtaugh, B. J. Schmitt, and K. S. Faaberg, 1999: Recombination between North American strains of porcine reproductive and respiratory syndrome virus. Virus Res. 61, 87-98.

Yuan, S., M. P. Murtaugh, and K. S. Faaberg, 2000: Heteroclite subgenomic RNAs are produced in porcine reproductive and respiratory syndrome virus infection. Virology 275, 158169.

Yuan, S., D. Mickelson, M. P. Murtaugh, and K. S. Faaberg, 2001: Complete genome comparison of porcine reproductive and respiratory syndrome virus parental and attenuated strains. Virus Res. 74, 99-110.

Yuan, S., M. P. Murtaugh, F. A. Schumann, D. Mickelson, and K. S. Faaberg, 2004: Characterization of heteroclite 
subgenomic RNAs associated with PRRSV infection. Virus Res. 105, 75-87.

Zell, R., A. Krumbholz, A. Henke, E. Birch-Hirschfeld, A. Stelzner, M. Doherty, E. Hoey, M. Dauber, D. Prager, and R. Wurm, 2000: Detection of porcine enteroviruses by nRT-PCR: differentiation of CPE groups I-III with specific primer sets. J. Virol. Methods 88, 205-218.

Zhou, Y. J., X. F. Hao, Z. J. Tian, G. Z. Tong, D. Yoo, T. Q. An, T. Zhou, G. X. Li, H. J. Qiu, T. C. Wei, and X. F. Yuan, 2008: Highly virulent porcine reproductive and respiratory syndrome virus emerged in China. Transbound Emerg Dis 55, 152-164.
Zhou, L., J. Zhang, J. Zeng, S. Yin, Y. Li, L. Zheng, X. Guo, $\mathrm{X}$. Ge, and H. Yang, 2009: The 30-amino-acid deletion in Nsp2 of highly pathogenic porcine reproductive and respiratory syndrome virus emerging in China is not related to its virulence. J. Virol 83, 5156-5167.

Zsak, L., M. V. Borca, G. R. Risatti, A. Zsak, R. A. French, Z. Lu, G. F. Kutish, J. G. Neilan, J. D. Callahan,

W. M. Nelson, and D. L. Rock, 2005: Preclinical diagnosis of African Swine Fever in contact-exposed swine by a real-time PCR assay. J. Clin. Microbiol. 43, 112-119. 